\title{
An artificial leucocyte control suspension
}

\author{
T. R. J. LAPPIN AND FRANCES M. SANDERSON \\ From the Department of Clinical Pathology, Royal Victoria Hospital, Belfast
}

SYNOPSIS Candida albicans grown under environmental conditions designed to yield the ${ }_{7}^{-}$ yeast form has been used as a leucocyte control. The yeast cells easily form an even suspen- $\frac{\mathbb{O}}{\mathrm{O}}$ sion, are approximately the same size as leucocytes, and are capable of withstanding conditions which cause red cell lysis. The suspension is stable on storage and is simple to prepare in large quantities.

The introduction of electronic cell counters or multitest haematological apparatus containing a channel for electronic counting has underlined the need for stable particle suspensions to permit a routine quality control programme.

Suitable red cell controls have been achieved by the use of glutaraldehyde-fixed red cells (Lewis and Burgess, 1966) and preserved human cells (Carville and Lee, 1969) and various artificial cell suspensions have been used such as polystyrene latex (Gabrielli and Wertheimer, 1961) but it is difficult to prepare an even suspension of latex particles within the required size range.

Fresh whole blood has been used to check the validity of leucocyte counts but the large amounts of blood needed for this purpose may make this not very practicable. In order to meet the need for a suitable leucocyte control we have used suspensions of the yeast Candida albicans killed by formaldehyde and suitably diluted.

\section{Method}

Using suitable aseptic technique, Candida albicans was subcultured from a nutrient agar slope into
$150 \mathrm{ml}$ aliquots of Sabouraud's liquid medium ${ }^{1} \stackrel{\circ}{\circ}$ contained in $300 \mathrm{ml}$ screw-capped bottles. The culture was incubated with occasional shaking ato $26^{\circ} \mathrm{C}$ for 72 hours. It was then centrifuged at $2,000 \mathrm{rpm}(700 \mathrm{~g})$ for five minutes and the supernatant removed by suction. The yeast cells in the deposit were killed by the addition of $20 \mathrm{ml}$ of a solution of formaldehyde $(10 \% \mathrm{v} / \mathrm{v}) \dot{0}$ in normal saline, transferred to a volumetric flask, and resuspended in $500 \mathrm{ml}$ of the formaldehyde/ $\odot$ saline solution.

In order to disperse the clumps the suspension응 was agitated vigorously with a magnetic stirrer $>$ for 16 hours. The supernatant liquid was again removed after centrifugation at $2,000 \mathrm{rpm}(700 \mathrm{~g}) \widehat{\mathrm{N}}$ for five minutes, and the cells were finally. resuspended in about $100 \mathrm{ml}$ of formaldehyde/ $N$ saline/Intradex ${ }^{2}$ solution $(1: 8: 1 \mathrm{v} / \mathrm{v})$. At this $\mathrm{N}_{\mathrm{N}}$ stage the yeast suspension was counted visually? in a counting chamber and if necessary furthero diluted with formaldehyde/saline/Intradex solution in order to give the desired counting value? within the range 10 to $25 \times 10^{3}$ cells per cmm.

During continuous magnetic stirring, $5 \mathrm{ml}$ 웅 aliquots of the suspension were removed and $\stackrel{\odot}{\circ}$ placed in screw-capped sample bottles which were $\stackrel{\mathbb{Q}}{\stackrel{Q}{Q}}$ stored at $4^{\circ} \mathrm{C}$ for use. 


\section{Discussion}

An artificial leucocyte control suspension should ideally consist of calls or particles which (1) easily form an even suspension and have a sedimentation rate similar to that of leucocytes; (2) have approximately the same size distribution as leucocytes; (3) are capable of withstanding conditions in which red cell haemolysis occurs; (4) are stable even after long storage; (5) are simple to prepare in large quantities.

Preliminary tests showed that yeast cells stored in formaldehyde/saline solution $(10: 90 \mathrm{v} / \mathrm{v})$ were easily resuspended by gentle mixing, but thereafter sedimented quickly in the sample containers. It was found that the addition of Intradex to a final concentration of $10 \%$ raised the viscosity of the suspending fluid sufficiently to give a sedimentation rate of yeast cells similar to that of leucocytes.

The diameter of leucocytes ranges from 3 to $5 \mu$ and yeast cells are from 5 to $12 \mu$. A discrepancy will therefore exist between the optimum threshold settings for leucocytes and yeast cells on a particular instrument. If the optimum leucocyte threshold setting is used, the observed yeast cell count will normally be less than the value obtained by a visual count. Since the purpose of the yeast suspension is to act as an artificial leucocyte control, each batch must be given a value, viz, a control count value. To achieve this end a particular instrument must first be calibrated by using samples of blood $\overline{\overline{o f}}$ which the white cell counts have been determin accurately by another method. Subsequently, the unknown yeast suspension is counted on the instrument, and the observed value is assigned $\overrightarrow{\vec{S}}$ the suspension for that particular instrument.

The formaldehyde-killed yeast suspension ff stable in both the acetic acid/cetrimide/formatr dehyde solution and saponin solution which a used as leucocyte diluting fluids for the SMA-7 and Coulter counter respectively.

The yeast control suspension stored at $4^{\circ} \vec{\sigma}$ has been counted regularly for over 12 months on both the SMA-7A and model A Coulters counter. No significant change was observed the counts, indicating very satisfactory stabilif on storage.

The suspension is simple to prepare, requiring about three hours' work and no special equipg ment in order to provide a large quantity $\circledast$ control suspension. For instance, 12 bottles of Sabouraud's medium cultured as described we found to supply sufficient yeast cell suspensio for our quality control system for one year.

In attempting to find the optimum conditions for growth, the $p \mathrm{H}$ of the Sabouraud's medium was raised from 5.7 to 7.3 by the addition increasing amounts of sodium hydroxide. This resulted in an approximately $50 \%$ elevation the number of cells, but there was also am
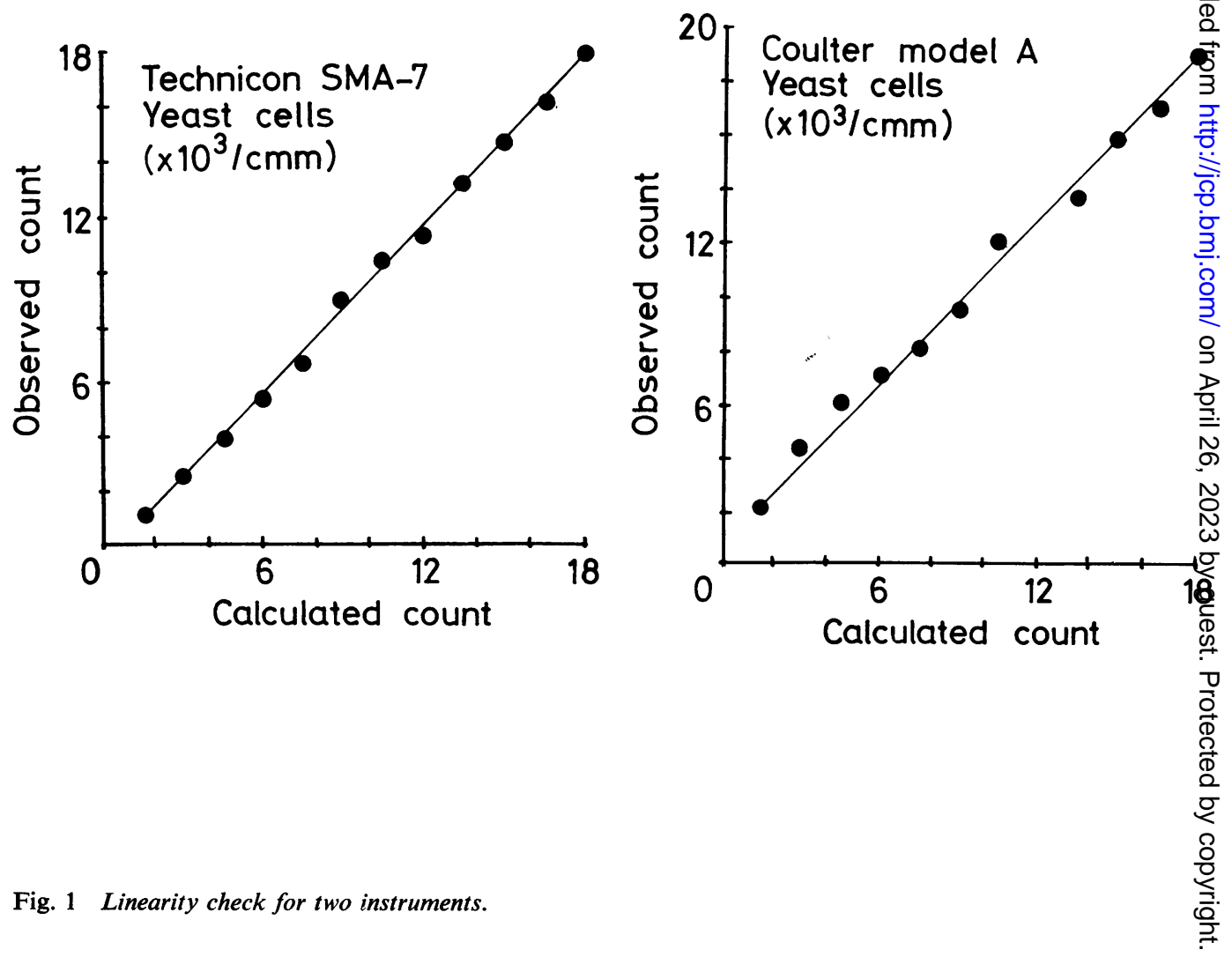


\begin{tabular}{|c|c|c|c|c|c|c|c|c|}
\hline & \multicolumn{4}{|c|}{ Technicon SMA-7 } & \multicolumn{4}{|c|}{ Model A Coulter Counter } \\
\hline & \multicolumn{2}{|c|}{ Leucocytes } & \multicolumn{2}{|c|}{$\begin{array}{l}\text { Yeast Control } \\
\text { Suspensions }\end{array}$} & \multicolumn{2}{|c|}{ Leucocytes } & \multicolumn{2}{|c|}{$\begin{array}{l}\text { Yeast Control } \\
\text { Suspensions }\end{array}$} \\
\hline & Low & High & Low & High & Low & High & Low & High \\
\hline $\begin{array}{l}\text { Number } \\
\text { Mean } \\
\text { Maximum } \\
\text { Minimum } \\
\text { SD } \\
\text { Coefficient of variation }\end{array}$ & $\begin{array}{l}20 \\
7 \cdot 52 \\
7 \cdot 8 \\
6 \cdot 8 \\
0 \cdot 27 \\
3 \cdot 6\end{array}$ & $\begin{array}{l}20 \\
17 \cdot 64 \\
18 \cdot 2 \\
17 \cdot 2 \\
0 \cdot 26 \\
1 \cdot 5\end{array}$ & $\begin{array}{l}20 \\
8 \cdot 86 \\
9 \cdot 2 \\
8 \cdot 5 \\
0 \cdot 27 \\
2 \cdot 9\end{array}$ & $\begin{array}{l}20 \\
18 \cdot 05 \\
18 \cdot 4 \\
17 \cdot 7 \\
0 \cdot 21 \\
1 \cdot 2\end{array}$ & $\begin{array}{l}20 \\
7 \cdot 21 \\
7 \cdot 6 \\
6 \cdot 7 \\
0 \cdot 34 \\
4 \cdot 7\end{array}$ & $\begin{array}{l}20 \\
18 \cdot 34 \\
17 \cdot 7 \\
18 \cdot 8 \\
0 \cdot 45 \\
2 \cdot 5\end{array}$ & $\begin{array}{l}20 \\
7 \cdot 70 \\
8 \cdot 4 \\
7 \cdot 1 \\
0 \cdot 38 \\
4 \cdot 9\end{array}$ & $\begin{array}{c}20 \\
17 \cdot 80 \\
8 \cdot 4 \\
17 \cdot 1 \\
0 \cdot 41 \\
2 \cdot 3\end{array}$ \\
\hline
\end{tabular}

Table 1 Comparison of preciston data ${ }^{1}$

${ }^{1}$ Cells $\times 10^{3}$ per cmm.

undesirable rise in the number of pseudomycelia observed. A report by Nickerson (1951) that the addition of cysteine $\left(10^{-2} \mathrm{M}\right)$ to the nutrient medium resulted in almost completely yeast-type growth prompted the investigation of the use of cysteine in Sabouraud's medium. It was found that the addition of cysteine did not lower the number of psudomycelia formed, which in any case is very small under the conditions described. To determine the effect of temperature on cell production, aliquots of the parent culture were incubated at room temperature, approximately $18^{\circ}, 26^{\circ}$, and $37^{\circ} \mathrm{C}$ for 72 hours. Those grown at $26^{\circ} \mathrm{C}$ gave the best yield. The optimum growth was therefore obtained by culturing the yeast cells in unaltered Sabouraud's medium, $p \mathrm{H} \mathrm{5.7,}$ at $26^{\circ} \mathrm{C}$ for 72 hours. These conditions consistently gave a good yield of cells which showed only an occasional small pseudomycelium per low-power microscope field.

Two instruments, such as the Coulter counter based on the principle of modulation of electrical conductivity, and the SMA-7A, based on the principle of light scattering, will show a difference in the result obtained with the same yeast suspension. However, the linearity of the cell count on both the SMA-7A and Coulter counter may be checked by using accurate dilutions of a yeast cell control suspension (Fig. 1).

The coefficient of variation for leucocyte and yeast suspension counts on the Technicon SMA-7A and on the model A Coulter did not differ significantly (Table I). Both instruments can, therefore, be considered to count yeast cells as precisely as leucocytes over the range 8.9 to $18.1 \times 10^{3}$ cells per $\mathrm{cmm}$.

The importance of the yeast suspension lies in its use as (1) a control count value and (2) as $_{T}$ a check on cell count linearity. If the threshold $\mathbb{\Phi}$ and other settings of the calibrated instrument are? not altered the assigned count value may be used to check the fidelity of leucocyte results obtained over a long period of time.

We are grateful to Dr M. G. Nelson for his interest and advice, and to Miss $\mathbf{J}$. Marshall and Miss $\mathbf{A} \cdot \frac{\bar{O}}{\mathrm{O}}$ Hardy for their skilled assistance.

\section{References}

Carville, J. M., and Lee, D. (1969). Red cell suspension as a working standard. J. clin. Path., 22, 738.

Gabrielli, E. R., and Wertheimer, M. (1961). Standardization of the electronic counter of blood cells. Amer. J. clin. Path. 36, 277-280.

Lewis, S. M., and Burgess, B. J. (1966). A stable suspension for? red-cell counts. Lab. Pract., 15, 305-306.

Nickerson, W. J. (1951). Physiological bases of morphogenesis in. animal disease fungi. Trans. N.Y. Acad. Sci., 13, 140-145. 